\title{
QUAL A PERCEPÇÃO DOS MORADORES DO ENTORNO DA RESERVA BIOLÓGICA AUGUSTO RUSCHI (ESPÍRITO SANTO, BRASIL) SOBRE OS ANFÍBIOS ANUROS?
}

\author{
WHAT IS THE PERCEPTION OF THE VILLAGERS FROM THE SURROUNDINGS OF \\ THE AUGUSTO RUSCHI BIOLOGICAL RESERVE (ESPÍRITO SANTO, BRAZIL) \\ ABOUT ANURANS?
}

Fernanda Cristina Lírio FERREIRA ${ }^{1 *}$ e Rodrigo Barbosa FERREIRA ${ }^{1}$

1Laboratório de Ecologia da Herpetofauna Neotropical, Programa de Pós-Graduação em Ecologia de Ecossistemas, Universidade Vila Velha, Avenida Comissão José Dantas de Melo, 21, Boa Vista II, CEP 29102-920, Vila Velha, Espírito Santo. *Autor para correspondência: nanda_clf@ hotmail.com

\section{RESUMO}

Submitted: 18/02/2019; Accepted: 03/05/2019

A Percepção Ambiental é um instrumento metodológico que possibilita o entendimento sobre o conhecimento popular e pode contribuir para criação ou reajuste de estratégias que visem o manejo e à conservação de áreas protegidas. O presente estudo envolveu a perspectiva dos moradores residentes no entorno de uma Unidade de Conservação em relação aos anfíbios anuros (sapo, rã e perereca), na tentativa de delinear um perfil do entendimento sobre crenças e juízos que as pessoas fazem destes animais. Entrevistas semiestruturadas com 18 moradores foram conduzidas em junho de 2016 em três comunidades no entorno da Reserva Biológica Augusto Ruschi, zona rural do município de Santa Teresa, Estado do Espírito Santo. Foi possível perceber que grande parte dos entrevistados possui conhecimentos sobre as diferenças morfológicas existentes entre os anfíbios anuros e sua ecologia. Sobre o sentimento dos entrevistados em relação aos sapos, pererecas e rãs, 22\% gostam desses animais, $40 \%$ são indiferentes. Sobre atitudes e reações, $77 \%$ nunca mataram esses animais. Isto nos leva a acreditar que os participantes lidam bem com esses animais, principalmente por conviverem e entenderem sua importância no meio ambiente. O histórico de educação familiar influencia a manutenção dos preconceitos, distanciamento e atitudes negativas em relação aos anfíbios anuros. Explorar o conhecimento popular e a forma como as pessoas interagem com o meio ambiente pode ser uma ferramenta para aliar a demanda ambiental e o desenvolvimento de estratégias à conservação da biodiversidade.

Palavras-chave: Conhecimento tradicional; Etnoherpetologia; Unidade de Conservação; Santa Teresa.

\begin{abstract}
Environmental Perception is a tool to evaluate how people can contribute to the management and conservation of protected areas. The present study involved the perspective of humans regarding amphibians, aiming at delineating a profile of the beliefs and judgments that people make of these animals. Semi-structured interviews with 18 residents were conducted in June 2016 in three communities in the surroundings of the Augusto Ruschi Biological Reserve, a rural area in the municipality of Santa Teresa, Espírito Santo State, Brazil. Most of the interviewees are aware of the ecology and the morphological differences between amphibians. About the respondents' feelings about toads and frogs, $22 \%$ like these animals, and $40 \%$ are indifferent. About attitudes and reactions, $77 \%$ never killed these animals. This leads us to believe that the participants deal well with these animals, mainly because they live together and understand their importance in the environment. The history of family education influences the maintenance of prejudices, distancing and negative attitudes toward amphibians. Exploring popular knowledge and how people interact with the environment can be a tool to combine human demands and biodiversity conservation.
\end{abstract}

Keywords: Traditional knowledge; Ethnoherpetology; Conservation Unit; Santa Teresa.

\section{INTRODUÇÃO}

Conhecer como as pessoas lidam e usam o meio ambiente é fundamental para elaboração de estratégias de conservação da biodiversidade. A etnociência é uma das áreas que permite alcançar este conhecimento (BEGOSSI, 1993). Para tanto, a Percepção Ambiental possui métodos para registrar o 
conhecimento popular das pessoas, abordando principalmente o modo como interagem e percebem o ambiente ao seu redor (CULLEN et al., 2012). Conhecer e refletir sobre os problemas ambientais locais são a base para a criação de estratégias para melhorias, devendo-se considerar o envolvimento das pessoas de forma participativa, principalmente no que tange aos aspectos culturais, econômicos e sociais da localidade (CULLEN et al., 2012). Desta forma é possível fundamentar futuras ações para a conservação da biodiversidade (BARBOSA, 2007).

A Mata Atlântica é um dos biomas mais ameaçados do mundo. Altamente fragmentada, hoje tem $14,5 \%$ de sua área original representada por remanescentes florestais (SOS MATA ATLÂNTICA e INPE, 2013). Esta redução acelerada de áreas naturais representa um dos grandes problemas ambientais enfrentados nas últimas décadas. Muito do que se tem preservado encontra-se dentro de Unidades de Conservação (UC). Estas áreas podem ser consideradas berçários por apresentarem características naturais relevantes e porque abrigam representantes importantes da biodiversidade, como, por exemplo, os anfíbios, que formam o grupo de vertebrados terrestre mais diverso do mundo (HADDAD, 2008) e um dos mais ameaçados de extinção (IUCN, 2019).

Os anfíbios são divididos em três ordens: Gymnophiona, Caudata e Anura. Este último, mais comum e numeroso, é representado pelos indivíduos que não têm cauda: sapo, rã e perereca. A maioria depende de ambiente aquático ou úmido para o desenvolvimento reprodutivo, e o período das chuvas é quando se tem os picos de atividade (FERREIRA et al., 2012; 2016).

Apesar de existirem muitos estudos voltados para o conhecimento da biodiversidade existente na Mata Atlântica, ainda são escassas pesquisas voltadas para o conhecimento popular sobre os anfíbios anuros. A ausência destes conhecimentos reduz as possibilidades de proteção deste grupo taxonômico e, consequentemente, do ecossistema como um todo (ALVES et al., 2010).

Deste modo, buscar o entendimento sobre a percepção que as pessoas têm do meio em que vivem pode embasar futuras ações que estimulem a reflexão sobre a importância das unidades de conservação, bem como da biodiversidade. Neste sentido, o objetivo deste estudo foi verificar a percepção de moradores sobre os anfíbios anuros na tentativa de compreender as relações cognitivas, comportamentais e simbólicas.

\section{MATERIAL E MÉTODOS}

\section{Área de estudo}

Desenvolvemos este estudo no entorno da Reserva Biológica Augusto Ruschi (RebioAR), inserida no bioma Mata Atlântica, município de Santa Teresa (1954'20" S, 40³3'44” W), Estado do Espírito Santo, sudeste do Brasil (Figura 1). No entorno da RebioAR existem cerca de 550 famílias e a maioria de suas residências faz divisa com os limites da RebioAR.
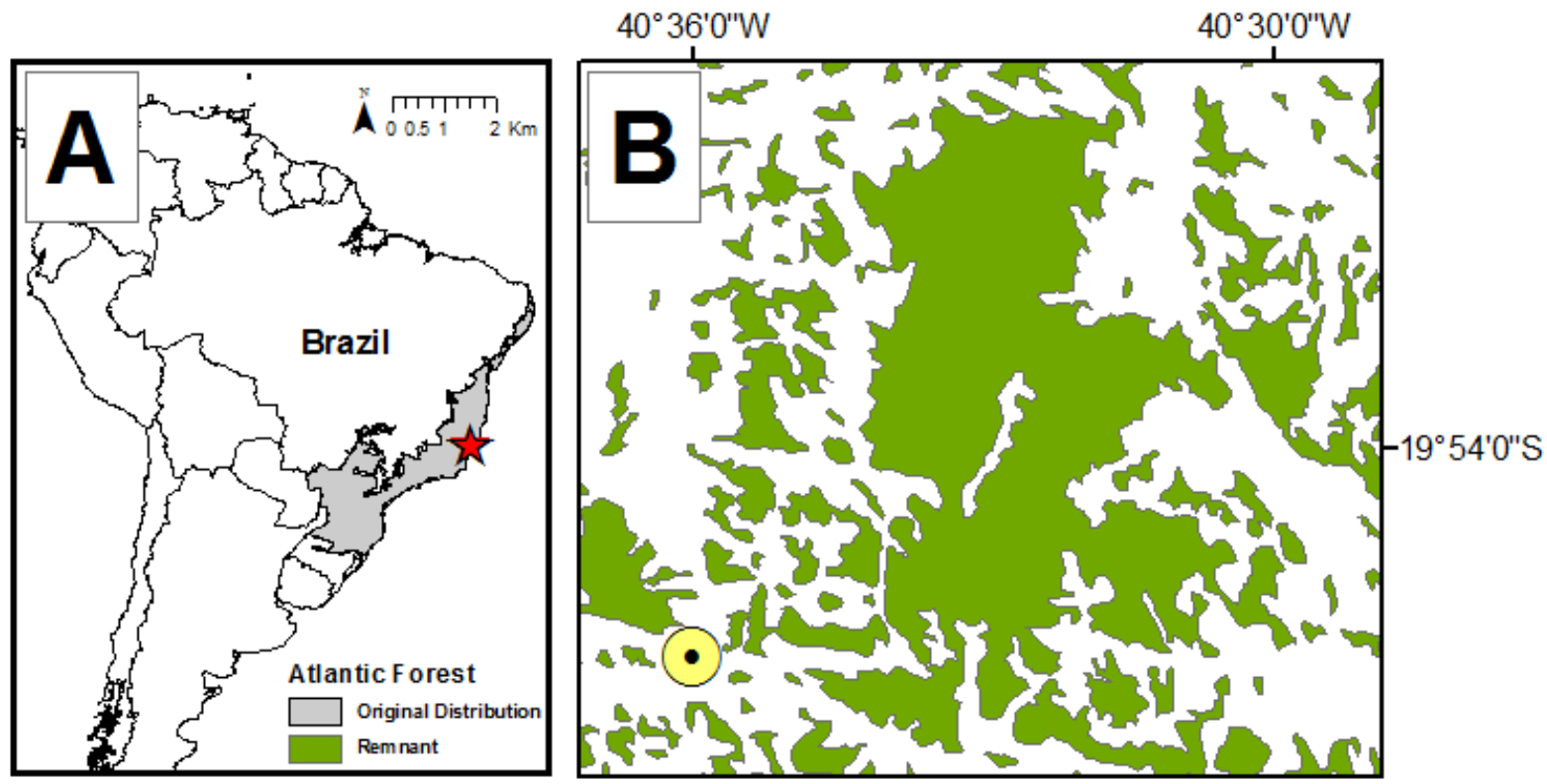

Figura 1: Localização do munícipio de Santa Teresa, Espírito Santo (A); remanescentes florestais e o bloco de mata da Reserva Biológica Augusto Ruschi (B). 


\section{Coleta de dados}

Primeiramente, realizamos visitas aos moradores das comunidades para explicar as intenções e os objetivos do estudo. Os interessados assinaram o Termo de Consentimento Livre e Esclarecido concordando em participar da pesquisa e cada entrevistado recebeu uma cópia do termo, enquanto os termos assinados estão mantidos com os autores deste estudo.

Baseando-se nos princípios da Percepção Ambiental (WHYTE, 1977), foi construído um roteiro semiestruturado (BERNARD, 1996) e a coleta de dados ocorreu em de junho de 2016. A maioria das perguntas foi aberta (WHYTE, 1977). A licença de coleta de dados foi concedida pelo Sistema de Autorização e Informação em Biodiversidade (SISBio, registro 50402).

\section{Análise de dados}

Os dados foram analisados a partir das dimensões adaptadas de Whyte (1977), explorando três variáveis: a primeira se refere às Variáveis de Estado que avaliam as características socioculturais; a segunda é a Variável de Saída que identifica o nível de conhecimento sobre os anfíbios anuros; a terceira variável é sobre os Processos de Percepção que investigam o que os anfíbios anuros representam para os entrevistados.

Para avaliar as dimensões supracitadas, as respostas das entrevistas foram categorizadas englobando elementos constitutivos de um conjunto por diferenciação e, seguidamente, por reagrupamento das respostas (ver BARDIN, 1977). Em complemento, algumas respostas foram utilizadas para construção da tabela cognitiva comparada, que busca checar o conhecimento popular com o existente na literatura científica (MARQUES, 1995).

\section{RESULTADOS E DISCUSSÃO}

No total, foram entrevistados 18 moradores e os resultados obtidos estão explicitados abaixo por dimensão e categoria que permitem avaliar as variáveis propostas.

\section{Dimensão 1 - Variáveis de Estado}

Dentre os 18 entrevistados, as mulheres foram as mais representativas com $67 \%(\mathrm{~N}=12)$, a maioria na faixa dos 50 anos. Os homens representaram 33\% (N=06) do número total de entrevistados, cuja maioria ficou entre 60 e 76 anos (Quadro 1).

Quadro 1 - Resultados sobre as Variáveis de Estado dos entrevistados.

\begin{tabular}{|c|c|c|}
\hline Características & Homem & Mulher \\
\hline Número de participantes & 06 & 12 \\
\hline \multirow{4}{*}{ Idade (anos) } & 01 com 29 & 03 com menos de 29 \\
\hline & 01 entre 50 e 59 & 02 entre 30 e 39 \\
\hline & 02 entre 60 e 69 & 06 entre 50 e 59 \\
\hline & 02 com mais de 70 & 01 com mais de 70 \\
\hline Tempo de moradia (anos) & \multicolumn{2}{|c|}{$\begin{array}{c}03(17 \%) \text { residem até } 5 \\
03(17 \%) \text { residem de } 6 \text { a } 20 \\
05(28 \%) \text { residem de } 21 \text { a } 30 \\
01(5 \%) \text { reside a } 36 \\
06(33 \%) \text { residem a mais de } 50\end{array}$} \\
\hline \multirow{3}{*}{ Escolaridade } & $01(5 \%)$ - não concluiu o EF & $13(75 \%)$ - não concluíram o EF \\
\hline & $01(5 \%)-$ concluiu o EF & $01(5 \%)$ - curso superior \\
\hline & $01(5 \%)-$ concluiu o EM & $01(5 \%)-$ Técnico \\
\hline \multirow{6}{*}{ Ocupação } & \multicolumn{2}{|c|}{$10(56 \%)$ agricultores } \\
\hline & \multicolumn{2}{|c|}{$03(17 \%)$ aposentados } \\
\hline & \multicolumn{2}{|c|}{$02(12 \%)$ estudantes } \\
\hline & \multicolumn{2}{|c|}{$1(5 \%)$ professor } \\
\hline & \multicolumn{2}{|c|}{$1(5 \%)$ dona do lar } \\
\hline & \multicolumn{2}{|c|}{$1(5 \%)$ operador de tratamento de esgoto } \\
\hline \multirow{4}{*}{ Religião } & \multicolumn{2}{|c|}{$13(73 \%)$ católicos } \\
\hline & \multicolumn{2}{|c|}{$03(17 \%)$ evangélicos } \\
\hline & \multicolumn{2}{|c|}{$01(5 \%)$ testemunha de Jeová } \\
\hline & \multicolumn{2}{|c|}{$01(5 \%)$ luterana } \\
\hline
\end{tabular}

Legenda: EF - Ensino Fundamental; EM - Ensino Médio. 
Ferreira e Ferreira. Qual a percepção dos moradores do entorno da Reserva Biológica Augusto Ruschi (Espírito Santo, brasil) sobre os anfíbios anuros? Ethnoscientia 4, 2019. DOI 10.22276/ethnoscientia.v4i1.208

\section{Dimensão 2 - Variáveis de Saída \\ Sobre as diferenças entre sapo, perereca e rã}

Todos os participantes $(\mathrm{N}=18)$ reconheceram que existem diferenças morfológicas entre os anfíbios anuros:

"O sapo tem o aspecto mais carachento, a perereca é mais lisinha. A cor vareia também, uns mais escuros outros mais claros."

"Tem uns pequenos, outras grandes. Tem perereca branca, verde, verde pintada de branca. $O$ sapo tem preto."

"[...] andando dá pra ver uns menorzinhos, mais verde. Tem um verdinho mais claro. Os que têm aqui são marrons mais escuros. No meio do mato dá pra ver. Acho que é perereca, é pequenininho assim [...]."

Provavelmente, este resultado esteja relacionado à moradia próximo às áreas florestadas, úmidas ou de reservatório de água, que são ambientes favoráveis a presença dos anfibios anuros, existindo assim maior probabilidade de contato visual e auditivo das pessoas com os sapos, pererecas e rãs. Um estudo na área rural do Nordeste do Brasil verificou que a presença de anfibios anuros em áreas agrícolas foi citada por 79\% dos entrevistados em Petrolândia e 65\% em Itacubura (Oliveira e Freire, 2015). Os autores observaram que os agricultores citaram a ocorrência de dez etnoespécies de rã, sapo e perereca, demonstrando que apesar do pouco conhecimento sobre a biologia dos anfibios anuros, os agricultores observam e reconhecem esses animais.

\section{Sobre anfíbio ser venenoso}

Onze (61\%) entrevistados afirmaram que os anfíbios apresentam veneno; quatro (22\%) disseram que não e três $(17 \%)$ pessoas não souberam responder, conforme exemplos abaixo:

"O leite branco, diz que é veneno."

"[...] acho que sapo mesmo não deve ter, acho que mais a rã ou a perereca tem."

"Já mijou na minha cara, mas não deu nada. Eu tinha medo, mas falaram que não faz nada. Acho que não tem veneno; só amarga, pois o cachorro já mordeu [...]."

A maioria dos participantes se posicionou negativamente em relação a anfíbio que possivelmente seja venenoso. A aceitação dos anfibios por parte dos seres humamos ainda é confusa, uma vez que há a crendice de que, principalmente, os sapos têm veneno e por isso as pessoas não se aproximam deles ou não os tocam. Em estudo realizado com alunos de uma escola urbana, $53 \%$ dos entrevistados afirmaram que a urina dos anfibios pode causar algum dano à saúde humana, como a cegueira (PAZINATO, 2013). Na área rural, o mesmo estudo mostrou que 54\% dos entrevistados também creem nesta informação. Além disso, 59\% acreditaram que sapo pode dar "cobreiro".

\section{Sobre presas e predadores dos anfíbios}

Os entrevistados demonstraram conhecimento sobre a ecologia dos anfíbios, especificamente sobre o hábito alimentar desses animais. Confiamos que este resultado esteja relacionado à presença destes animais próximos às residências. Quinze (83\%) participantes responderam que estes animais comem moscas e borboletas. Sobre predadores dos anfibios anuros, as respostas foram: cinco pessoas (29\%) citaram a cobra e cinco (29\%) citaram o gavião, seguidas de três $(17 \%)$ citações para lagartos; para peixe, araçari, galinha, porco e rato houve uma (5\%) citação para cada.

"Comem mosca, borboleta, insetos pequenos."

"[...] já vi o sapo grande embaixo da lâmpada pegando mosquito."

"Cobra né? Tem o araçari, o tucano que comem sapo [...]."

"[...] já vi sapo na boca da cobra. O sapo grita. O sapo passa apertado. Eu vou lá e tiro o sapo [....]."

Os anfíbios desempenham funções importantes nos ecossistemas aquático e terrestre, como presas constituem parte significativa da alimentação de muitos animais. Como predadores, podem ser controladores de pragas ou insetos transmissores de doenças. Em um estudo sobre a ecologia dos anfíbios realizado com moradores do entorno da APA do Rio Curiaú no Amapá, 65\% dos entrevistados 
declararam que os "sapos" comem insetos (LIMA et al., 2017) e que são predados por répteis, aves e mamíferos (WOEHL, 2007).

\section{Sobre o nicho temporal dos anfíbios}

Entre os 18 participantes, 16 (89\%) responderam que veem e ouvem mais esses animais durante a noite, uma vez que os anuros frequentam os quintais e varandas à noite, rodeando as luzes dos postes em busca de insetos para se alimentarem; dois (11\%) entrevistados falaram que os observavam mais durante o dia, notadamente durante a panha do café, pois algumas pererecas esverdeadas e brancas ficam escondidas aderidas as folhas do café . Sobre a sazonalidade dos anfibios, ou seja, em que época do ano esses animais estão em atividade, 15 (83\%) entrevistados responderam que escutam sapo, perereca e rã vocalizarem no final do ano, na época quente. Os outros três (17\%) entrevistados associaram a vocalização desses animais à época chuvosa. Isto demonstra que apesar de alguns serem animais pequenos e crípticos, os anfíbios anuros não são invisíveis aos olhos e ouvidos das pessoas no cotidiano. De fato, durante o dia os anuros permanecem imóveis e sua aparência pálida e pele úmida causam repulsa aos agricultores (OLIVEIRA e FREIRE, 2015). Algumas espécies de pererecas se aderem às folhas da vegetação durante o dia para se esconderem/descansarem mediante a camuflagem (FERREIRA et al., 2019).

Em ambos os temas (período de atividade e sazonalidade) houve resultado compatível com o conhecimento científico quanto ao conhecimento geral acerca dos anfíbios anuros por parte dos entrevistados. De forma geral, todos os entrevistados associaram o período reprodutivo dos anfíbios anuros à época chuvosa e sua atividade ao período noturno. Percebe-se que o conhecimento popular dos moradores do entorno da RebioAR é condizente com o conhecimento científico. Tais semelhanças são essencialmente sobre as características físicas dos anfibios, modo de vida e comportamento (Tabela 1).

Tabela 1 - Cognição comparada entre citações e relatos dos entrevistados acerca do modo de vida dos anfíbios e a literatura científica sobre o tema.

\begin{tabular}{|c|c|}
\hline Conhecimento popular & Conhecimento científico \\
\hline “Vejo mais de noite." & São animais de hábito noturno (PIMENTA et al., 2014). \\
\hline $\begin{array}{l}\text { "Vejo mais no verão." } \\
\text { “Verão, outubro e novembro." }\end{array}$ & $\begin{array}{l}\text { Devido à dependência da umidade, o período das chuvas } \\
\text { é aquele onde os anfíbios são encontrados em seus picos } \\
\text { de atividade (PIMENTA et al., 2014). }\end{array}$ \\
\hline "Comem mosca, borboleta, insetos pequenos." & $\begin{array}{l}\text { Os anfíbios, na fase adulta, alimentam-se geralmente de } \\
\text { invertebrados, incluindo insetos. (HADDAD et al., } \\
\text { 2008). }\end{array}$ \\
\hline "O leite branco, diz que é veneno." & $\begin{array}{l}\text { O gênero Rhinella apresenta as } \\
\text { glândulas granulares, que liberam uma } \\
\text { substância de aspecto leitoso, com } \\
\text { capacidade de provocar irritabilidade } \\
\text { nos predadores (DUELLMAN e TRUEB, } \\
\text { 1994; NARVAES e RODRIGUES, 2009). }\end{array}$ \\
\hline "Controla os insetos." & $\begin{array}{l}\text { O grupo dos anfíbios tem grande importância como } \\
\text { controladores de populações de invertebrados e de } \\
\text { outros vertebrados (PIMENTA et al., 2014). }\end{array}$ \\
\hline $\begin{array}{c}\text { "Já mijou na minha cara, mas não deu nada. Eu } \\
\text { tinha medo, mas falaram que não faz nada. Acho } \\
\text { que não tem veneno, só amarga, pois o cachorro } \\
\text { já mordeu." }\end{array}$ & $\begin{array}{l}\text { A urina dos anfíbios não apresenta perigo a nenhum ser } \\
\text { vivo. Os anuros urinam para amedrontar e afastar o } \\
\text { predador (COLOMBO e ZANK, 2008). Algumas } \\
\text { espécies de anfíbios, como da família Bufonidae, podem } \\
\text { secretar substância capaz de causar irritabilidade nos } \\
\text { predadores (NARVAES e RODRIGUES, 2009). }\end{array}$ \\
\hline “A rã pode comer." & $\begin{array}{l}\text { A espécie Leptodactylus latrans (rã manteiga) é } \\
\text { considerada cinegética, pois comumente é utilizada para } \\
\text { fins de consumo humano (PIMENTA et al., 2014). }\end{array}$ \\
\hline "São comidos por cobra." & $\begin{array}{l}\text { Constituem uma importante fonte alimentar para as } \\
\text { serpentes (HADDAD et al., 2008). }\end{array}$ \\
\hline $\begin{array}{c}\text { "O sapo tem o aspecto mais carachento. A } \\
\text { perereca é mais lisinha. A cor vareia também, uns } \\
\text { mais escuros outros mais claros." }\end{array}$ & $\begin{array}{l}\text { É importante ressaltar que os anfíbios anuros } \\
\text { normalmente apresentam algumas variações de colorido } \\
\text { e morfologia (PIMENTA et al., 2014). }\end{array}$ \\
\hline
\end{tabular}


Quatorze (78\%) entrevistados indicaram o desmatamento e falta de água que a região vem sofrendo nos últimos anos para justificar a ausência ou diminuição dos anfíbios anuros; quatro (22\%) pessoas não souberam responder. Podemos constatar nas seguintes respostas:

"Sim, oito anos atrás tinha mais, quando tinha o poço a gente via os ovinhos. Hoje não vê mais nada. Hoje a noite não canta mais."

"[...] antigamente era muita chuva, tinha um barulhão de sapo e agora não se vê mais [...]."

"A gente não observa muito, mas deve ter diminuído muito, pelo que ouve da destruição da natureza, pelo uso de veneno, algumas espécies devem até ter sumido. Os que ficam na mata tão mais salvos [...]."

Os entrevistados percebem e apontam claramente as causas para a redução dos anfíbios anuros no ambiente natural e os problemas enfrentados por eles. Contudo, nenhum morador abordou a palavra "conservação" e nem relacionou a existência de uma Unidade de Conservação (RebioAR) com ações conservacionistas. Os desmatamentos no entorno da RebioAR, ocorrentes desde a colonização italiana em Santa Teresa, colaboraram significativamente tanto para as mudanças da paisagem quanto às depleções faunísticas que presenciamos atualmente (FERREIRA et al., 2016).

Os moradores do entorno de uma Reserva Particular do Patrimônio Natural em Minas Gerais apontaram o desaparecimento de alguns animais nativos, como o coelho (tapeti) devido à ausência de habitat natural favorável a eles; uma moradora diz: "Hoje não tem mais bicho como antigamente" (MESQUITA, 2004). De acordo com as respostas observadas em um estudo etnozoológico no município rural de Caçapava do Sul, Rio Grande do Sul, verificou-se que a maioria dos entrevistados (41\%) indicou que a redução dos anfíbios e répteis tem forte ligação com as atividades humanas, apontando, assim, o impacto negativo para a preservação destes grupos de animais (PAZINATO, 2013).

O nível de conhecimento sobre as causas e as consequências, oriundas de atitudes negativas, pode provocar a diminuição ou desaparecimento dos anfíbios anuros, e muitas vezes este fato está ligado à falta de oportunidade das pessoas de conhecerem o grupo em questão durante sua vida, ou de terem maior contato com eles.

\section{Dimensão 3 - Processos de percepção \\ Sentimento do entrevistado sobre os anfíbios}

Pedimos para cada participante definir com uma palavra o seu sentimento ao ver um sapo, perereca ou rã. As respostas e número de citações foram as seguintes: sete (40\%) afirmaram ser indiferente, dois (11\%) se sentem felizes, dois (11\%) gostam, um (5\%) sente rejeição, dois (11\%) sentem nojo, três $(17 \%)$ sentem medo, e uma (5\%) pessoa não soube responder. Este resultado representa que $22 \%$ das pessoas têm bons sentimentos (gostam e se sentem felizes) em relação aos anfíbios anuros. Uma pesquisa realizada em uma comunidade quilombola no Estado do Amapá registrou que 59\% das pessoas têm medo de sapo (LIMA et al., 2017). Em um estudo realizado com estudantes do ensino fundamental e médio, $30 \%$ e $25 \%$ respectivamente, disseram não sentir medo ao ver um sapo, perereca ou rã (DIAS et al., 2018). Estes mesmos autores também observaram o oposto, pois 37\% (ensino fundamental) e 33\% (ensino médio) dos estudantes disseram sentir nojo ao ver algum desses animais.

A forma como as pessoas percebem, identificam, categorizam e classificam o mundo natural intervém no seu modo de pensar, agir e expressar emoções com relações aos animais (COSTA-NETO e PACHECO, 2004). Esses autores ressaltaram que normalmente os seres humanos apresentam atitudes e sentimentos de desdém, temor e aversão por animais que são culturalmente percebidos como "insetos". De forma geral, a relação dos seres humanos com outros animais pode variar de acordo com a influência de vários fatores, como, por exemplo: sensação tátil e visual; noção de sujeira ou limpeza; benefícios ou prejuízos oriundos do animal; ameaças relacionadas à saúde do ser humano; conhecer ou não conhecer sobre o animal (MORALES et al., 1997).

\section{Interações com os anfíbios}

Dentre os 18 entrevistados, 11 (61\%) afirmaram nunca ter tido contato físico com sapos, pererecas e rãs, cinco (28\%) disseram que já os pegaram nas mãos e duas (11\%) disseram que apenas tiveram contato tátil com rãs.

\footnotetext{
"Já peguei."

"Sim. Nunca me fez nada."
} 
"Eu acho que o sapo pode e a perereca não, né? Pode dar alguma micose. A rã eu creio que possa."

"Eu não pego não [...] na peneira, panhando café, ela pulou aqui. Deus me livre!"

"Nunca peguei na mão. Tenho medo. Se pular em mim eu acho que morro. É muito esquisito."

"Não, é um bicho que não se pega na mão. Tem que deixar quieto pra lá. Sabe por quê? Esses que ficam no terreiro no quintal, soltam leite. E aquele leite eu não sei o que é que pode provocar, então não pode pegar na mão."

Podemos constatar que os entrevistados apresentam contato visual frequente com estes animais por residirem e trabalharem em zona rural, principalmente em ambientes favoráveis para sua ocorrência. Contudo, alguns entrevistados têm receio de tocar nesses animais por medo de contrair alguma doença. Em um estudo realizado com crianças sobre a periculosidade de Amphisbaenia (réptil), percebeu-se que não havia certeza nas respostas, como no seguinte exemplo de uma citação: “[...] acho também que não seja perigosa não, mas os mais velhos falam que ela mata rápido [...]" (COSTA-NETO e PACHECO, 2004). Segundo estes autores, isto demonstra a falta de segurança da criança sobre o conhecimento acerca do animal. Muitas pessoas deixam de interagir com os anfíbios por acreditarem que, ao tocar em um sapo, pegariam alguma micose (cobreiro) (SALLA et al., 2017). Em um estudo realizado com estudantes de ensino médio e fundamental, $95 \%$ dos entrevistados já ouviram falar sobre a urina de sapo cair nos olhos e provocar cegueira (DIAS et al., 2018). De fato, este é um argumento bastante difundido e provavelmente está relacionado ao tipo de conhecimento sobre determinado animal que as pessoas recebem dos que estão ao seu entorno, sendo então recepção e repetição de informações sem fundamento.

\section{Atitudes e reações}

Verificamos que 14 entrevistados (77\%) disseram não ter matado anfíbio, quatro (23\%) disseram ter jogado sal ou matado algum anuro. Vejamos algumas das respostas:

"Não, sempre saio fora."

"Sim, já matei."

"Não, nunca matei. Quando passa carro em cima do sapo eu fico com dó."

"Uma vez joguei sal."

"Não! É pecado isso."

Apesar de a maioria ter dito que não matou nenhum anfíbio, percebemos certa rejeição das pessoas, dando a entender que esses animais causam algum incômodo. Em estudos sobre percepção de anuros em uma comunidade de quilombolas, $65 \%$ afirmaram que nunca jogaram sal nos sapos e disseram não conhecer alguém que já tenham feito isso (LIMA et al., 2017).

Os anfíbios notadamente pertencem a um dos grupos de animais mais rejeitados pelos seres humanos (COSTA-NETO e PACHECO, 2004). Essa rejeição pode ser explicada pelo afastamento das pessoas com o mundo natural, permitindo assim que as atitudes negativas se tornem genéricas para quase todos os animais (HOYT e SCHULTZ, 1999). Em contrapartida, acreditamos que as reações positivas estejam relacionadas com a frequente presença desses animais próximos às residências dos entrevistados. Em estudo semelhante, a maioria dos entrevistados (47\%) diz agir normalmente quando encontram um sapo (LIMA et al., 2017). No entanto, em uma comunidade rural, 19\% das pessoas disseram jogar sal, empurrar e espantar os sapos, pois acreditam que eles são capazes de "lançar" seu veneno ou "leite" nas pessoas, ou ainda pela aversão à pele úmida e fina, típica da maioria dos anuros (PINTO, 2011).

\section{Importância e utilidade dos anfíbios anuros}

Os entrevistados entendem os anfíbios anuros como: controladores de insetos (56\%); como alimento para outros animais (22\%); importantes na cadeia alimentar (17\%); uso na medicina (5\%). Estes resultados podem ser constatados nas seguintes respostas:

"Só se for pra fazer limpeza, comer os insetos, os mosquitos."

"[...] se não tiver o sapo pra cobra se alimentar e como vai ser? E a cobra precisa do remédio dela pra fazer remédio de pressão." 


\section{"[...] porque o inimigo do agricultor é o inseto. Eu sempre preservei esses bichos." \\ "Cadeia alimentar, um vai comendo o outro [...]." \\ "Creio pra mim que é antídoto pra saúde, porque eles tiram das cobras e acho que dos sapos também [...]." \\ "A rã comem."}

Mais da metade dos entrevistados deste estudo percebe a importância dos anfíbios anuros para o controle de insetos. Em estudo realizado com duas comunidades do entorno de uma Área de Preservação Ambiental sobre a importância dos anfíbios, a maioria dos entrevistados (76\%) sabe que são importantes, mas eles não souberam explicar como; além de que $94 \%$ dos entrevistados responderam que se todos os sapos do mundo desaparecessem, ocorreriam desequilíbrios no meio ambiente, mas também não souberam dizer quais seriam as consequências diretas (LIMA et al., 2017). Em estudos realizados em áreas agrícolas, no Estado de Pernambuco, 37\% dos agricultores de Petrolândia e 48\% de Itacuruba demonstraram algum conhecimento sobre o sapo cururu (Rhinella sp.), dando a entender que este sapo pode contribuir para o controle da população de insetos, pois afirmaram que os cururus são os responsáveis pela "limpeza do ambiente agrícola" (OLIVEIRA e FREIRE, 2015). Pesquisadores afirmam que o declínio das populações de anfíbios afeta negativamente o funcionamento ecossistêmico, a saúde e alimentação humana, pois estes animais fazem o controle biológico de insetos considerados pragas em plantações, como também fazem o controle de insetos vetores de doenças (VALENCIA et al., 2013).

Quando questionados se sapo, perereca e rã podem ser consumidos por humanos, 15 (83\%) responderam que somente as rãs podem ser usadas na alimentação humana. Apesar desta afirmação, os entrevistados finalizaram as respostas dizendo que eles próprios não têm o costume de comer ou que nunca comeram. Em um estudo realizado com moradores rurais foi constatado que um dos usos dos anfíbios citados foi exatamente o da alimentação, em específico a rã (gia) do gênero Leptodactylus (OLIVEIRA, 2011).

\section{Ameaças e histórias}

Quanto às ameaças dos anuros aos seres humanos, sete entrevistados (39\%) afirmaram que os anfíbios anuros podem causar alguma doença, oito (44\%) não souberam responder e três (17\%) disseram que estes animais não transmitem nada. Algumas respostas:

\footnotetext{
"[...] Eu penso pode dar cobreiro. Muitas vezes a perereca mijou em cima e corri pra lavar logo e passar álcool, porque eu tenho tanto nojo."

"Já peguei girino na mão, mas minha mãe não gosta, pensa que traz doença."

"Minha mãe dizia que aquilo dá cobreiro na gente."

"Meus avós diziam que podia pegar cobreiro e o xixi cega. Talvez, se pegar, na defesa dele pode soltar alguma coisa que dá coceira , né!?”."

"Não sei se passam doença. Um pouco das histórias eles inventam"

"Não dá doença."
}

Esta ameaça que os seres humanos apontam, de forma geral, está relacionada com a herança cultural que as pessoas passam para seus filhos ou netos a fim de protegê-los. Podemos constatar isso ao observarmos que alguns dos entrevistados disseram se lembrar dos avós ou pais alertando-os para terem cuidado e não tocar no sapo, perereca ou rã, pois poderiam pegar alguma doença.

Geralmente as pessoas caracterizam determinados animais como asquerosos e se distanciam deles por se sentirem ameaçadas. Em uma pesquisa realizada com alunos de sete a oito anos, em escolas rural e urbana, pode-se verificar que as crianças, de ambas as escolas, apontaram os anfíbios anuros como nojentos feios e perigosos (RIBEIRO et al., 2012); esses autores destacam ainda que as crianças trazem consigo a herança de um preconceito instalado em seu meio advindo de seus pais. Conceitos prédeterminados na fase de desenvolvimento das crianças afetam diretamente as relações com o meio ambiente. A sociedade é que constrói determinados conceitos sobre a natureza, não sendo naturais estes julgamentos, mas sim implantados culturalmente (PORTO-GONÇALVES, 1990).

Quanto às histórias, nove entrevistados (50\%) disseram que já ouviram alguma história sobre os anfibios, sete pessoas (39\%) disseram não saber de nenhuma história e duas (11\%) não souberam responder. Em nossas entrevistas, constatamos que as histórias estão relacionadas ao medo e rejeição. Algumas das respostas: 
"Não, de sapo quase não vê falando."

"Não, minha mãe nunca cultivava essas coisas. Tudo é natureza, deixar vivo."

"Não, não. Só essa mesmo de que não era bom ficar brincando com eles, pra não fazer xixi no olho [...] eu não sei se é verdade, a gente aprende com os pais, ele passam pra gente, né."

"Não, só falavam que os que soltam leite são venenosos, não pode mexer."

"Não. Os velhos eram ignorantes. Eles até matavam, eles são mal informados."

"A minha vó, ela jogava sal pra espantar [...]."

"Única coisa que minha mãe falava esses de preferência que fica perto de casa [...] deixar o bicho quieto, porque quando urina voa dentro do olho da pessoa."

Há um consenso intrafamiliar muito grande entre os níveis de sensibilidade ao nojo dos pais e as várias medidas de fobias aos animais demonstradas pelos filhos (DAVEY et al., 1993). As crianças imitam as reações dos pais em respostas às criaturas desejadas ou não a sua volta. Neste caso, as reações podem ter relação direta com a informação transferida sobre quem são anfíbios e sua importância. Lauck (2002) evidencia que ensinar as crianças a terem nojo ou medo, impede que elas explorem a experiência positiva com os animais mais adiante. Estudos comprovam que fatores ligados à emoção interferem e direcionam a percepção e o número de informações a respeito do elemento (ANDERSON, 2004). Desta maneira, para o animal que é tido como asqueroso, feio e transmissor de doenças, normalmente o conhecimento a seu respeito será inferior (SOUZA e SOUZA, 2006).

De certa forma, situações assim acabam por afastar prováveis simpatizantes, observadores ou mesmo futuros estudantes interessados em pesquisas (PAZINATO, 2013). Esta demanda pode ser reduzida, principalmente, por meio de ações educativas em ambientes formal e informal.

\section{CONCLUSÃO}

Constatamos, tanto pelas categorias utilizadas quanto pela comparação cognitiva, que grande parte dos entrevistados possui conhecimento sobre as diferenças morfológicas existentes entre os anfíbios anuros, sobre sua ecologia, importância para o ecossistema e para os humanos. Associamos estes conhecimentos à convivência constante das pessoas com estes animais.

Ao investigarmos sobre quais utilidades os anuros apresentam, verificamos que os entrevistados não fazem uso de rãs para alimentação, mas a maioria tem o conhecimento desta utilidade. Grande parte dos entrevistados demonstrou não ter bons sentimentos ao mencionarmos os sapos, pererecas e rãs. Possivelmente, este resultado esteja relacionado com o preconceito e sobre a crendice dos anfíbios serem venenosos ou por oferecerem alguma ameaça à saúde humana.

As histórias lembradas e contadas pelos entrevistados foram sempre associadas somente ao medo e rejeição, levando-nos a acreditar que este distanciamento e as atitudes negativas estão ligadas à bagagem histórica que as pessoas carregam consigo, pois ainda hoje reproduzem os prejulgamentos ditados por seus antepassados. Desta forma, muitas das reações negativas podem ter relação direta sobre o tipo de informação que está sendo transmitida no meio, por exemplo, sobre quem são os anfíbios e sua importância para o ecossistema.

Incluir as comunidades no plano de manejo da Reserva Biológica Augusto Ruschi é uma oportunidade de promover a conservação da biodiversidade local. Além disso, ações de Educação Ambiental podem contribuir substancialmente para oferecer conhecimento às pessoas e sensibilizá-las em relação aos anfíbios, bem como da fauna e flora em geral. Assim, é possível que os moradores do entorno da RebioAR compreendam a importância da preservação da biodiversidade e dos recursos naturais, agindo de forma prática em favor da sustentabilidade.

\section{AGRADECIMENTOS}

Agradecemos ao Projeto Bromeligenous pelo apoio logístico em campo.

\section{REFERÊNCIAS}

ANDERSON, J. R. Psicologia cognitiva e suas implicações experimentais. Rio de Janeiro: Livros Técnicos e Científicos. 2004. 
AQUIJE, G. M. F. V.; SANTOS, I. K. F. Levantamento florístico de pteridófitas da Reserva Biológica Augusto Ruschi, Santa Teresa-ES. Revista Brasileira de Biociências, v. 5, n. 2, p. 909-911, 2007.

BARBOSA, A. R. Os humanos e os répteis da mata: uma abordagem etnoecológica de São José da Mata - Paraíba. João Pessoa-PB. 2007. Dissertação (Prodema) - Universidade Federal da Paraíba, João Pessoa, 2007.

BARDIN, L. Análise de conteúdo. Lisboa: Edições 70, 1977.

BEGOSSI, A. Ecologia humana: um enfoque das relações homem-ambiente. Interciência, v. 18, p. 121-132, 1993.

BERNARD, H. R. Research methods in anthropology: qualitative and quantitative approaches. American Journal of Evaluation, v. 17, p. 91-92, 1996.

COLOMBO, P.; ZANK, C. Informações gerais sobre anfíbios. In: BOND-BUCKUP, G. (Org.). Biodiversidade dos Campos de Cima da Serra. 1. ed. Porto Alegre: Libretos, 2008. p. 104-111.

COSTA-NETO, E. M.; PACHECO, J. M. A construção do domínio etnozoológico "inseto" pelos moradores do povoado de Pedra Branca, Santa Terezinha, Estado da Bahia. Acta Scientiarum. Biological Sciences Maringá, v. 26, n.1, p. 81-90, 2004.

CULLEN JR. L.; RUDRAN, R.; VALLADARES-PÁDUA, C. Métodos de estudos em biologia da conservação e manejo da vida silvestre. 2. ed. Curitiba: Editora UFRP, 2012.

DIAS, M. A. S.; LIMA, N. B.; FIGUEIREDO-DE-ANDRADE, C. A. Análise do conhecimento etnoherpetológico dos estudantes no município de Salinas, Minas Gerais, Brasil. Acta Biomedica Brasiliensia, v. 9 , n.1, p. 36-47, 2018.

DUELLMAN, W. E.; TRUEB, L. Biology of amphibians. Baltmore: The Johns Hopkins University Press, 1994.

FERREIRA, R. B.; DANTAS, R. B.; TONINI. J. F. R. Distribuição espacial e sazonal de anfíbios em quatro poças na região serrana do Espírito Santo, sudeste do Brasil: influência de corredores florestais. Série Zoologia, Iheringia, v. 102, p. 163-169, 2012

FERREIRA R. B.; BEARD K. H.; CRUMP M. L. Breeding guild determines frog distributions in response to edge effects and habitat conversion in the Brazil's Atlantic Forest. PLoS ONE, v. 11, p. 1-13, 2016.

FERREIRA, R. B.; LOURENÇO-DE-MORAES, R.; ZOCCA, C.; DUCA, C.; BEARD, K. H.; BRODIE Jr.; E. D. Antipredator mechanisms of post-metamorphic anurans: a global database and classification system. Behavioral Ecology and Sociobiology, v. 73, p. 769, 2019.

FUNDAÇÃO SOS MATA ATLÂNTICA, INSTITUTO NACIONAL DE PESQUISAS ESPACIAIS. Atlas dos remanescentes florestais da Mata Atlântica, período 2011-2012. São Paulo: SOS Mata Atlântica, 2013.

HADDAD, C. F. B., TOLEDO, L. F., PRADO, C. P. A. Anfíbios da Mata Atlântica: guia dos anfíbios anuros da Mata Atlântica. São Paulo: Editora Neotrópica, 2008.

HADDAD, C. F. B. Anfíbios: uma análise da Lista Brasileira de Anfíbios Ameaçados de Extinção. In: MACHADO, A.B.M.; DRUMMOND, G.M.; PAGLIA, A.P. (eds.). Livro vermelho da fauna brasileira ameaçada de extinção. Brasília: Ministério do Meio Ambiente, 2008.

HOYT, E.; SCHULTZ, T. Insect lives: stories of mystery and romance from a hidden world. Cambridge: Harvard University Press, 1999.

IUCN. Red List of Threatened Species. Version 2019-1. Disponível em: 〈https://www.iucnredlist.org>. Acesso em 18 abr. 2019.

LIMA, J. R. F.; LIMA, J. D.; SILVA, R. B. L.; ANDRADE, G. V. De. Percepção de anfíbios na Área de Proteção Ambiental do Rio Curiaú, Macapá, Amapá, Brasil. In: BASTOS, A. M.; MIRANDA JUNIOR, J. P.; LIMA E SILVA, R. B. (Orgs.). Conhecimento e manejo sustentável da biodiversidade amapaense. São Paulo: Blucher, 2017. p. 91-118.

LUCENA, M. M. A.; FREIRE, E. M. X. Percepção ambiental por uma comunidade rural do entorno de uma reserva particular do patrimônio natural (RPPN), semiárido brasileiro. 2011. Educação Ambiental em ação, n. 35, ano IX. Disponível em: <http://www.revistaea.org/artigo.php?idartigo=991>. Acesso em: 24 set. 2018.

MARQUES, J. G. W. Pescando pescadores: ciência e etnociência em uma perspectiva ecológica. 2. ed. São Paulo: Nupaub/USP, 1995.

MESQUITA, E. D. dos S. Percepções e usos da fauna silvestre pelas comunidades humanas do entorno da reserva particular do patrimônio natural do Caraça, Catas Altas/Santa Barbara, MG. 2004. 92 f. Dissertação (Mestrado em Zoologia de Vertebrados de Ambientes Impactados). Pontifícia Universidade Católica de Minas Gerais, Belo Horizonte, 2004.

NARVAES, P.; RODRIGUES, M. T. Taxonomic revision of Rhinella granulosa species group (Amphibia, Anura, Bufonidae), with a descripton of a new species. Arquivos de Zoologia, v. 40, n. 1, p. 1-73, 2009.

OLIVEIRA, E. S. Uso e conservação da fauna por populações humanas no Rio Grande do Norte, nordeste do Brasil. 2011. 94 f. Dissertação (Mestrado em Ecologia). Universidade Federal do Rio Grande do Norte, Natal, 2011.

OLIVEIRA, I. S.; FREIRE, E. M. X. Conhecimento ecológico local sobre anfíbios anuros por agricultores em sistemas agrícolas de região semiárida brasileira. Revista Brasileira de Ciências Ambientais (Online), v. 36, p. 202-207, 2015. 
PAZINATO, D. M. M. Estudo etnoherpetológico: conhecimentos populares sobre anfíbios e répteis no município de Caçapava do Sul, Rio Grande do Sul. 2013. 65 f. Monografia (Especialização em Educação Ambiental) - Universidade Federal de Santa Maria, Santa Maria, 2013.

PIMENTA, B.; COSTA, D.; MURTA-FONSECA, R.; PEZZUTI, T. Anfíbios: Alvorada de Minas, Conceição do Mato Dentro, Dom Joaquim, Minas Gerais. Belo Horizonte: Bicho do Mato, 2014.

PINTO, L. C. L. Etnozoologia e conservação da biodiversidade em comunidades rurais da Serra do Ouro Branco. Ouro Preto, MG. 2011. 84 f. Dissertação (Mestrado em Ecologia de Biomas Tropicais) Universidade Federal de Ouro Preto, Ouro Preto, 2011.

PORTO-GONÇALVES, C. W. Os (des)caminhos do meio ambiente. São Paulo: Contexto, 1990.

QUEIROZ, H. L.; PERALTA, N. Reserva de desenvolvimento sustentável: manejo integrado dos recursos naturais e gestão participativa. In: GARAY, I.; BECKER, B.K. (Orgs). Dimensões humanas da biodiversidade: o desafio das relações sociedade natureza no século XXI. 1. ed. Petrópolis: Editora vozes, 2006. p. 447-483.

RIBEIRO, C. D. L.; RIBEIRO, P.P.; IRIAS, N. G.; SILVA, M. T. H. Educação Ambiental: desvendando a concepção das crianças em relação aos anfíbios anuros. Revista Mediação, v. 1, p. 54-65, 2012.

SALLA, R. F.; COSTA, M. J.; FERNANDES, H. L. Influência do sistema afetivo-emocional no aprendizado: valores culturais e mitificação dos anfíbios anuros. Revista de Ensino de Biologia, v. 10, n. 1, p. 87-105, 2017.

SILVA, T. S.; CÂNDIDO, G. A; FREIRE, E. M. X. Conceitos, percepções e estratégias para conservação de uma estação ecológica da caatinga nordestina por populações do seu entorno. Uberlândia, Sociedade \& Natureza, v. 21, n. 2, p. 23-37, 2009.

SOUZA, C. E. P. DE; SOUZA, J. G. DE. (Re)conhecendo os animais peçonhentos: diferentes abordagens para a compreensão da dimensão histórica, sócio-ambiental e cultural das ciências da natureza. 2006. Disponível em: <http://abrapecnet.org.br/atas_enpec/venpec/conteudo/artigos/1/pdf/p847.pdf>. Acesso em: 25 maio 2017.

VALENCIA A.; CORTES A. M.; RUIZ C. A. Ecosystem services provided by amphibians and reptiles in Neotropical ecosystems. International Journal of Biodiversity Science, Ecosystem Services \& Management, v. 9, n. 3, p. 2-16. 2013.

WHYTE, A. V. T. Guidelines for field studies in environmental perception. Paris: UNESCO, 1977.

WOEHL, JR. G., WOEHL, E. N. Características dos anfíbios. 2007. Disponível em: <http://www.rabugio.org.br/downloads/cartilha_anfibios.pdf>. Acesso em: 10 maio 2017. 